\title{
An Abnormal MRI Signal in Both Lateral Geniculate Bodies Is a Diagnostic Indicator for Patients with Behçet's Disease
}

\author{
Yuka Ogawa $^{\mathrm{a}}$ Michitaka Nakagawa $^{\mathrm{a}}$ Masahide Yazaki $^{\mathrm{a}} \quad$ Shu-ichi Ikeda ${ }^{\mathrm{a}}$ \\ Sayuri Shu ${ }^{\mathrm{b}}$
}

Departments of a Medicine, Neurology and Rheumatology, and ${ }^{b}$ Ophthalmology, Shinshu University School of Medicine, Matsumoto, Japan

\section{Key Words}

Behçet's disease · Lateral geniculate body · Visual field defects

\begin{abstract}
A few case reports involving Behçet's disease have described visual field defects ascribed to the lateral geniculate body; however, no cases of lesions in both lateral geniculate bodies have been reported. A 50-year-old male who had fever and genital ulceration 3 months earlier noticed visual field defects. A T2-weighted MRI and FLAIR image showed highintensity lesions in both lateral geniculate bodies. The posterior end of the optic tracts and lateral geniculate bodies were bilaterally enhanced with gadolinium. Because of the presence of three (aphthous stomatitis, genital ulceration and uveal inflammation) of the four major symptoms, the patient was diagnosed with an abortive type of Behçet's disease and started predonisolone at a dose of $0.5 \mathrm{mg} / \mathrm{kg}$, after which he showed a rapid improvement of all symptoms. The lesions in the lateral geniculate bodies had disappeared on the MRI images taken 2 weeks after treatment onset. In addition to Behçet's disease, several case reports have observed lesions in both lateral geniculate bodies. Their visual field defects disappeared within half a year, in parallel with the healing process of the primary diseases. The pathogenesis of the lesions in both lateral geniculate bodies in these cases is believed to be related to the underlying disorders, especially vascular involvement from inflammation. The appearance of lesions in both lateral geniculate bodies on MRI scans may indicate the presence of systemic inflammatory diseases such as Behçet's disease, but further examinations are required.




\section{Introduction}

Behçet's disease is a chronic systemic inflammatory disorder that frequently involves oral and/or genital mucosa, ocular uvea and skin. When the central nervous system is predominantly affected, the condition is called neuro-Behçet's disease. A few case reports involving Behçet's disease have described visual field defects ascribed to cerebral lesions, especially in the lateral geniculate body [1,2]; however, no case reports have observed lesions in both lateral geniculate bodies. Here, we report a neuro-Behçet's disease patient whose initial manifestation was visualized as lesions in both lateral geniculate bodies on magnetic resonance image (MRI).

\section{Case Presentation}

A 50-year-old man with fever and genital ulceration 3 months earlier noticed visual loss in both eyes when waking. Although this visual loss resolved within $10 \mathrm{~min}$, a visual field defect persisted. A few days later, the patient visited a neurosurgery hospital where MRI revealed abnormal signals in both lateral geniculate bodies (fig. 1a). The patient was referred for further examination. He was suffering from fever $\left(38-39^{\circ} \mathrm{C}\right)$ and aphthous stomatitis. Goldman visual field examination showed bilateral incomplete homonymous hemianopia (fig. 2a). Laboratory data revealed increased serum levels of fibrinogen and CRP, an accelerated blood sedimentation rate (fibrinogen: $446.6 \mathrm{mg} / \mathrm{dl}$, normal: $180-350 \mathrm{mg} / \mathrm{dl}$; CRP: $2.47 \mathrm{mg} / \mathrm{dl}$; blood sedimentation rate: $55 \mathrm{~mm} / \mathrm{h}$ ) and HLA-A26 was positive. Lumbar puncture revealed an increased number of cells and elevated levels of interleukin- 6 as well as total protein in cerebrospinal fluid (number of cells: 15/ $\mu$; interleukin-6: $48 \mathrm{pg} / \mathrm{ml}$, normal: $\leq 15 \mathrm{pg} / \mathrm{ml}$; total protein: $72 \mathrm{mg} / \mathrm{dl}$, normal: $\leq 40 \mathrm{mg} / \mathrm{dl}$ ). The T2-weighted MRI and FLAIR images showed high-intensity lesions in both lateral geniculate bodies (fig. 1b); however, the size of these lesions was reduced compared with that of previously observed lesions. The posterior end of the optic tracts and lateral geniculate bodies were bilaterally enhanced with gadolinium, but the optic nerves and optic chiasm were not (fig. 1c-f). Optical coherence tomography showed a macular edema on the left retina (fig. 2c), and fluorescein fundus angiography in both eyes revealed a fernlike fluoro-leak image (fig. 2d), both of which indicated posterior uveitis. Because of the presence of three (aphthous stomatitis, genital ulceration and uveal inflammation) of the four major symptoms, the patient was diagnosed with an abortive type of Behçet's disease and was started on predonisolone (PSL) at a dose of $0.5 \mathrm{mg} / \mathrm{kg}$, after which he showed a rapid improvement of all symptoms. The lesions in the lateral geniculate bodies had disappeared on MRI images taken 2 weeks after treatment onset, and the visual field defects had improved (fig. $2 \mathrm{~b}$ ). Methotrexate was added from day 50 at a dose of $6 \mathrm{mg} /$ week and was increased to $8 \mathrm{mg} /$ week on day 70, while the dose of PSL was decreased gradually to $18 \mathrm{mg} /$ day. On day 115, the patient had an optical attack of Behçet's disease; since this attack, he has been treated additionally with infliximab.

\section{Discussion}

Two cases with Behçet's disease presenting with signal abnormalities in one of the lateral geniculate bodies have been previously reported [1, 2]. Both cases were diagnosed with Behçet's disease a few years earlier and subsequently developed visual field defects, the cause of which was considered ischemic damage from vasculitis. The patients were treated 
with PSL and showed a partial recovery of their visual field defects. Unlike these 2 cases, our case had lesions in both lateral geniculate bodies. In addition to Behçet's disease, there have been several cases with lesions in both lateral geniculate bodies [3-5], in which the underlying disorders were inflammatory bowel disease, acute pancreatitis and anaphylactic shock. Although these patients commonly suffered from bilateral incomplete hemianopia, their visual field defects disappeared within half a year in parallel with the healing processes of the primary diseases. Thus, the pathogenesis of the lesions in both lateral geniculate bodies in these cases is believed to be related to the underlying disorders, especially the vascular involvement from inflammation. In our case, it is noteworthy that the lesions in both lateral geniculate bodies on MRI were a predominant manifestation of Behçet's disease, leading to a definitive diagnosis using additional detailed ophthalmologic examinations. Based on all of the cases mentioned above, the appearance of lesions in both lateral geniculate bodies on MRI may indicate the presence of systemic inflammatory diseases such as Behçet's disease and that further examinations are required.

\section{Acknowledgments}

This study was supported in part by a Health and Labor Sciences Research Grant on Intractable Diseases (neuroimmunological diseases) from the Ministry of Health, Labor and Welfare of Japan.

\section{References}

-1 Takahashi J, Masaki H, Hayashi K, Inoue M, Jimi T, Wakayama Y: A case of neuro-Behcet disease with homonymous quadrantanopsia due to an inflammatory lesion involving the lateral geniculate body (in Japanese). Rinsho Shinkeigaku 2006;46:410-414.

-2 Iseri PK, Altun N, Akansel G: Homonymous quadrantanopia secondary to Behçet disease. Neuroophthalmology 2012;36:6-8.

3 Conor M, Jayne B, Jan R, Euqene K, Brendan L: Bilateral sectoranopia caused by bilateral geniculate body infarction in a 14-year-old boy with inflammatory bowel disease. J AAPOS 2010;14:435-437.

4 Lefèbvre P, Cordonnier M, Balériaux D, Chamart D: An unusual cause of visual loss: involvement of bilateral lateral geniculate bodies. AJNR Am J Neuroradiol 2004;25:1544-1548.

5 Mudumbai RC, Bhandari A: Bilateral isolated lateral geniculate body lesions in a patient with pancreatitis and microangiopathy. J Neuroophthalmol 2007;27:169-175.

Y.O., M.N. and S.I. contributed equally to this work. 


\begin{tabular}{l|l}
\hline Case Rep Neurol 2014;6:78-82 \\
\hline DOI: $10.1159 / 000360848$ & $\begin{array}{l}\text { (c) 2014 S. Karger AG, Basel } \\
\text { www.karger.com/crn }\end{array}$ \\
\hline
\end{tabular}

Ogawa et al.: An Abnormal MRI Signal in Both Lateral Geniculate Bodies Is a Diagnostic Indicator for Patients with Behçet's Disease
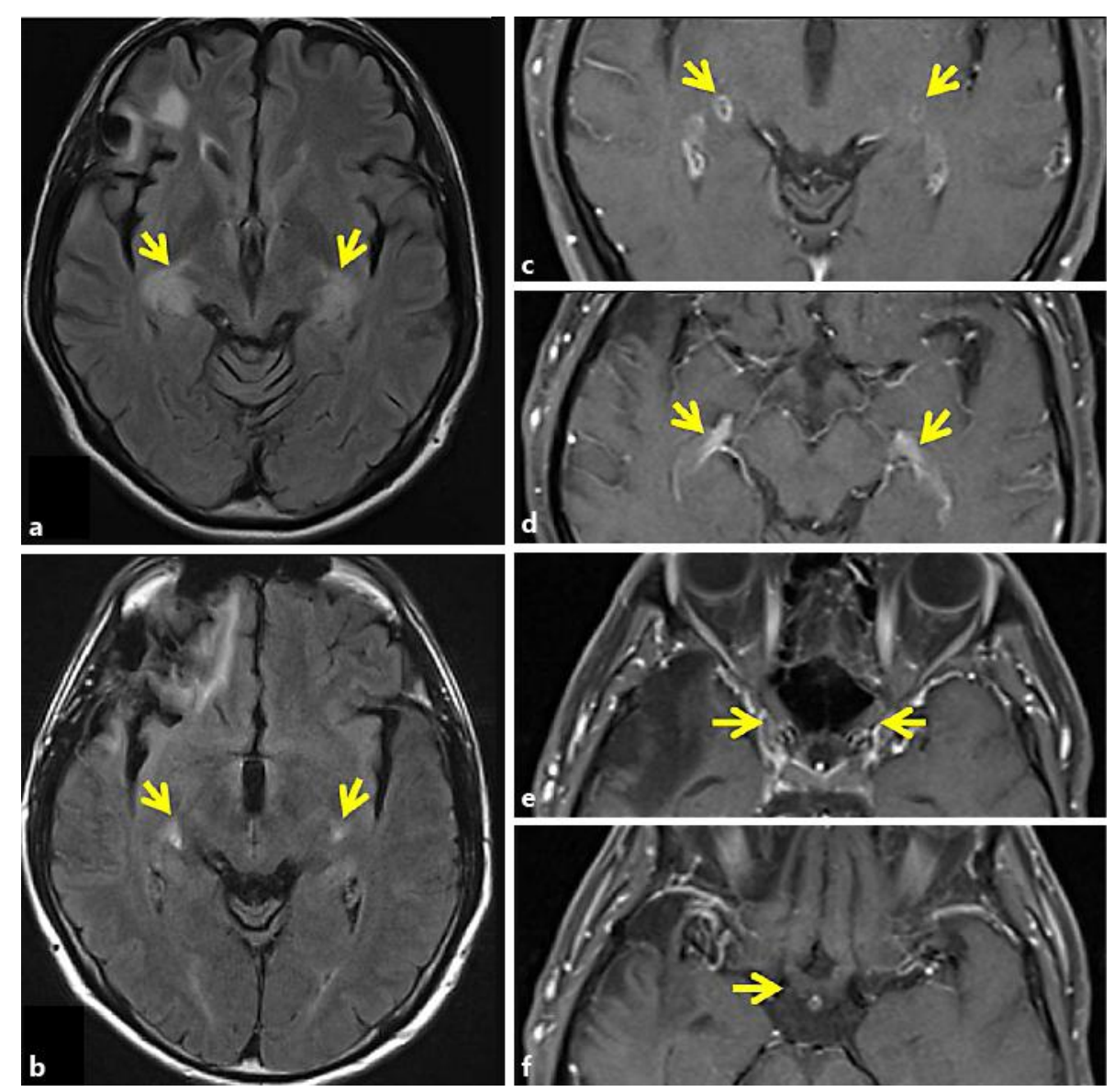

Fig. 1. MRI findings in the brain. a FLAIR image at day 1 showing abnormal signals in both lateral geniculate bodies, indicated by arrows. The left frontal lesion is an old traumatic lesion. b FLAIR image at day 20 showing high-intensity lesions in both lateral geniculate bodies, the size of which is reduced compared to a. c The lateral geniculate bodies and the posterior end of the optic tracts (d) were bilaterally enhanced with gadolinium, but the optic nerves (e) and optic chiasm (f) were not. 

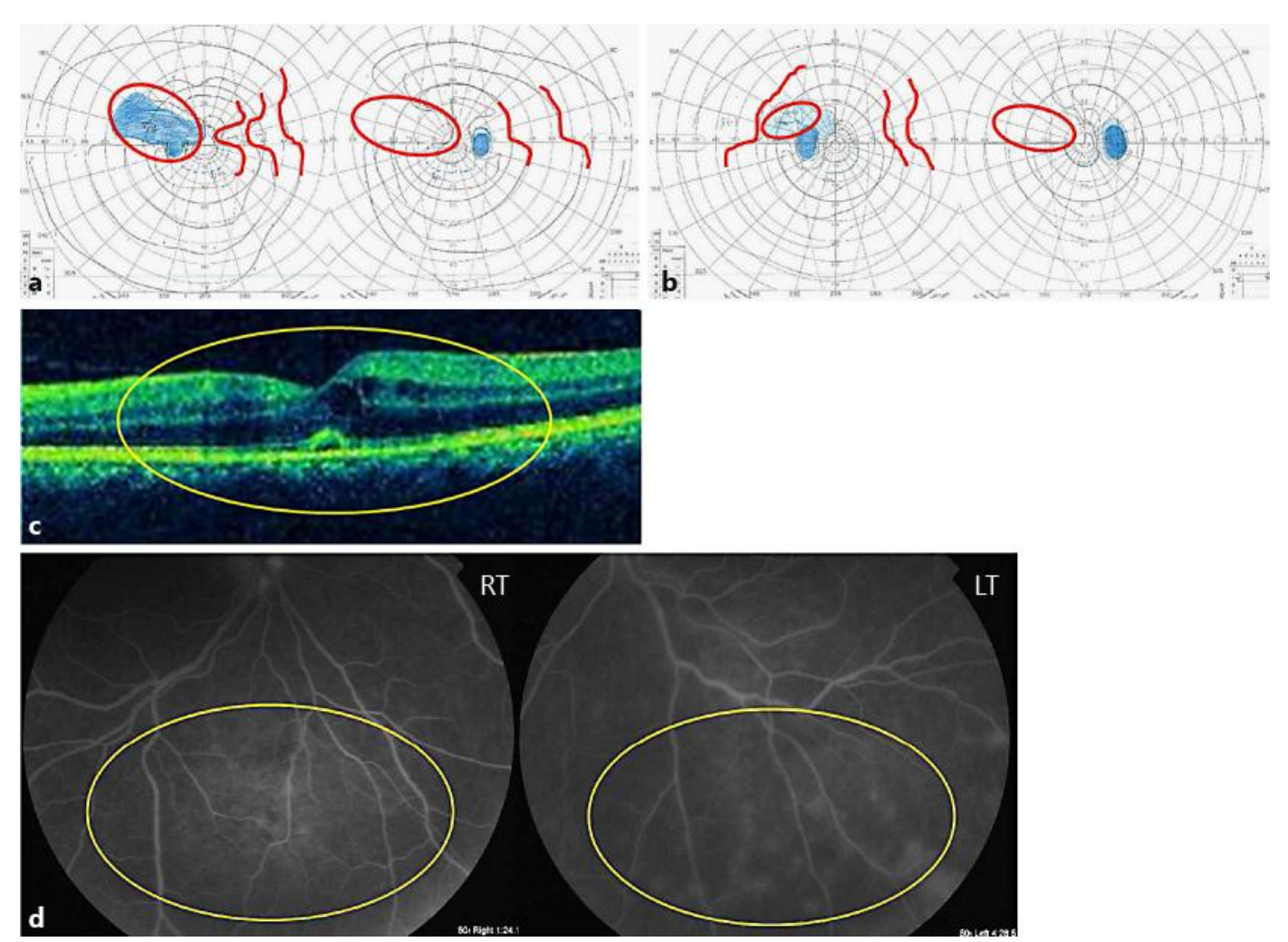

Fig. 2. Ophthalmologic findings. a Goldman visual field examination showing bilateral incomplete homonymous hemianopia. b Visual field defects were relieved 2 weeks after treatment. c Optical coherence tomography showing a macular edema on the left retina. $\mathbf{d}$ Fluorescein fundus angiography in both eyes showing characteristic fernlike fluoro-leak images. $\mathrm{Rt}=$ Right side, $\mathrm{Lt}=$ left side. 